$12-9-2020$

\title{
Evolution of Tidal Marsh Distribution under Accelerating Sea Level Rise
}

\author{
Molly Mitchell \\ Virginia Institute of Marine Science \\ Julie Herman \\ Virginia Institute of Marine Science \\ Carl Hershner \\ Virginia Institute of Marine Science
}

Follow this and additional works at: https://scholarworks.wm.edu/vimsarticles

Part of the Marine Biology Commons

\section{Recommended Citation}

Mitchell, Molly; Herman, Julie; and Hershner, Carl, Evolution of Tidal Marsh Distribution under Accelerating Sea Level Rise (2020). Wetlands, 40, 1789-1800.

DOI: 10.1007/s13157-020-01387-1

This Article is brought to you for free and open access by the Virginia Institute of Marine Science at W\&M ScholarWorks. It has been accepted for inclusion in VIMS Articles by an authorized administrator of W\&M ScholarWorks. For more information, please contact scholarworks@wm.edu. 
5 Authors: Molly Mitchell ${ }^{1}$, Julie Herman ${ }^{2}$, and Carl Hershner ${ }^{3}$

$6 \quad{ }^{1}$ Virginia Institute of Marine Science, William \& Mary, Gloucester Point, VA, USA

$7 \quad{ }^{2}$ Virginia Institute of Marine Science, William \& Mary, Gloucester Point, VA, USA

$8 \quad{ }^{3}$ Virginia Institute of Marine Science, William \& Mary, Gloucester Point, VA, USA

11 Corresponding author: Molly Mitchell (molly@vims.edu), (804) 684-7931 (phone)

13 Author Contributions:

14 All authors contributed to the study conception and design. Modeling and data analysis were 15 performed by M. Mitchell and J. Herman. The first draft of the manuscript was written by M. 16 Mitchell and all authors commented on previous versions of the manuscript. All authors 17 approved the final manuscript. 
20 Tidal marshes are important ecological systems that are responding to sea level rise-driven

21 changes in tidal regimes. Human development along the coastline creates barriers to marsh

22 migration, moderating tidal marsh distributions. This study shows that in the Chesapeake Bay, an

23 estuarine system with geographic and development variability, overall estuarine tidal marshes are

24 projected to decline by approximately half over the next century. Tidal freshwater and

25 oligohaline habitats, which are found in the upper reaches of the estuary and are typically backed

26 by high elevation shorelines are particularly vulnerable. Due to their geological setting, losses of

27 large extents of tidal freshwater habitat seem inevitable under sea level rise. However, in the

28 meso/poly/euhaline zones that (in passive margin estuaries) are typically low relief areas, tidal

29 marshes are capable of undergoing expansion. These areas should be prime management targets

30 to maximize future tidal marsh extent. Redirecting new development to areas above $3 \mathrm{~m}$ in

31 elevation and actively removing impervious surfaces as they become tidally inundated Results in

32 the maximum sustainability of natural coastal habitats. Under increasing sea levels and flooding,

33 the future of tidal marshes will rely heavily on the policy decisions made, and the balance of

34 human and natural landscapes in the consideration of future development.

36 Key Words

37 Tidal marsh; sea level rise; marsh migration; ecological conflicts

\section{$38 \quad 1$ Introduction}

39 Tidal marsh loss is a significant issue throughout the United States and there is growing concern

40 about accelerating sea level rise and the impact it will have on marsh persistence. Significant

41 marsh loss may dramatically change coastal and estuarine functions and potentially impact 
42 global nutrient/biogeochemical cycles (Chmura, 2013; Coverdale et al., 2014). Marsh loss

43 associated with sea level rise, erosion and human activity has been documented throughout the

44 United States (e.g. Nyman et al., 1994; Hartig et al., 2002; Bromberg \& Bertness, 2005; Mitchell 45 et al., 2017).

47 Tidal marsh extents are defined by the interaction of landscape elevations and tidal regime. As

48 sea levels rise and the maximum extent of tidal inundation reaches higher elevations, tidal

49 marshes are induced to migrate inland to maintain their place in the tidal frame. In areas with

50 low coastal elevations, tidal marshes can expand or maintain their size as they migrate across the

51 landscape, resulting in a potential future gain of tidal marshes (e.g., Kirwan et al., 2016).

52 However, in areas with higher elevations or where migration paths are blocked by shoreline

53 structures or impervious surfaces, marsh loss has been documented (Mitchell et al., 2017). Tidal

54 marshes along shorelines with high banks (steep slopes) or stabilized shorelines and those

55 comprising marsh islands have limited migration potential and are at particular risk of reduction

56 under sea level rise. Although elevation is the primary control on marsh migration potential, as

57 marshes migrate inland they also conflict with development, particularly impervious surfaces.

58 This conflict is likely to increase in importance since coastal zones are not only more densely

59 populated than inland areas but also show a trend of increasing population growth and

60 urbanization (Neumann et al., 2015). Within the coastal zone, populations tend to be clustered in

61 the lowest elevation areas (Small \& Nicholls, 2003), which are prime areas for marsh migration

62 and expansion. Development patterns in urbanizing areas are a controlling factor in habitat loss

63 (Bierwagen et al., 2010). In coastal areas, future development patterns may intersect with marsh

64 migration corridors, affecting the persistence of tidal marsh ecosystems. 
66 In addition to human land use patterns affecting the expansion of the landward edges of marshes,

67 high erosion rates lead to accelerated seaward edge marsh loss. Shoreline erosion rates are

68 predicted to increase with sea level rise, exacerbating marsh loss (Leatherman et al., 2000). On

69 high energy, moderate gradient slopes, high erosion rates have the potential to outpace landward

70 migration, resulting in shrinking marsh extent. High erosion rates are also associated with

71 proliferation of shoreline stabilization structures designed to protect developed areas but these

72 can actively block marsh migration pathways. Shoreline hardening currently occurs on $14 \%$ of

73 the U.S. coastline (Gittman et al., 2015) and in the Chesapeake Bay, approximately 18\% of all

74 tidal shorelines are already hardened (Bilkovic \& Mitchell, 2017).

75

76 The question of future marsh persistence is incomplete without consideration of changes in the

77 types of marsh habitat and their position in the landscape. Many marsh functions (e.g., enhanced

78 shoreline stabilization, Shepard et al., 2011; provision of nekton refuge habitat, Minello et al.,

79 2012) are reliant on a wide-spread distribution of marshes along shorelines, while some (e.g.,

80 modifiers of nutrient loads from upland, Valiela \& Cole, 2002) require their persistence in the

81 upper portion of the estuary where they can effectively intercept groundwater and overland flow

82 (Arheimer et al., 2004). Furthermore, freshwater marshes support unique floral and faunal

83 communities that are not replicated in higher salinity marshes.

84

85 This study uses shorelines from the Virginia portion of the Chesapeake Bay (henceforth

86 "CBVA" as opposed to "Chesapeake Bay" which refers to the entire system) to model potential

87 changes in marsh area, habitat provision and location under accelerating sea level rise. The 
88 Chesapeake Bay is the largest estuary in the United States. Its long, crenulated shoreline means

89 there are marshes of all shapes and sizes along the edges of the Chesapeake Bay and its

90 tributaries. CBVA coastal areas include both rural and highly urbanized waterfronts -and cover a

91 wide range of erosive energy and geomorphic settings (CBVA population is slightly more than

925.5 million people, $86 \%$ of which live in one of 2 urban coastal regions; 2017 population

93 statistics, US. Census data). Recent rates from around the Chesapeake Bay are in the range of 4-

946 mm/yr (Ezer \& Atkinson, 2015; Boon \& Mitchell, 2015) exceeding the rate of recent global

95 sea level rise (based on satellite altimetry), which is around $3.2 \mathrm{~mm} / \mathrm{yr}$ (Church \& White, 2011;

96 Ezer, 2013). This extreme rate is attributed to multiple factors including changes in global sea

97 level in combination with regional and local land subsidence (Boon, 2012; Eggleston \& Pope,

98 2013) and shifts in the Gulf Stream Current location and speed (Ezer, 2013). With these high

99 rates of relative sea level rise, and with evidence that those rates are accelerating (Boon \&

100 Mitchell, 2015; Boon et al., 2018), the CBVA is a perfect laboratory for investigating the balance

101 between forces affecting tidal marsh persistence into the future.

102

103 Sea level rise has led to an increase in flooding (Ezer \& Atkinson, 2014; Sweet \& Park, 2014)

104 and an interest in flooding adaptations that reduce impacts to human infrastructure. The desire to

105 protect infrastructure from flooding can constrain the potential space for marsh migration,

106 affecting future marsh distributions (e.g., Feagin et al., 2010). To explore the balance between

107 the geographically-controlled capacity of marshes to migrate landward with rising sea levels and

108 the constraints of adjacent human land use, we project the movement of tidal marsh elevations

109 across the landscape under an accelerating sea level rise scenario, allowing examination of how

110 different factors impact future marsh distributions. 
112 The CBVA is generally representative of regional tidal estuaries, containing a diverse array of

113 tidal marsh types and ecologies, geologic settings, and human settlements. The CBVA estuary

114 (Figure 1) consists of the mainstem bay (with long fetches and flat, coastal plain shorelines) and

115 estuarine rivers (with variable topography and fetches). It possesses a wide range of salinities

116 from approximately $35 \mathrm{ppt}$ near the mouth of the CBVA, to $0 \mathrm{ppt}$ in the upper reaches of the

117 estuarine rivers and in the small tributary creeks found along their edges. Currently, there are

118 approximately $761 \mathrm{~km}^{2}$ of tidal marshes, with a mix of salinity types consisting of about 25\%

119 tidal freshwater marsh, 15\% oligohaline marshes, 30\% brackish and 30\% salt marsh (TMI;

120 CCRM, 2017). Marshes are spread extensively along the shoreline, with concentrated pockets

121 of salt marsh areas in some bay-front localities and tidal freshwater marsh areas in the upper

122 tributaries. The tributary rivers split the landscape into four peninsulas, creating corridors of

123 development that expand outward from old harbors. Because of this, areas of concentrated

124 development are predominately in the Hampton Roads region (comprised of Newport News and

125 Hampton on the lower Peninsula, and Norfolk, Virginia Beach, Chesapeake, and Portsmouth on

126 the lower Southside) and the Northern Virginia region (comprised of Alexandria, Arlington,

127 Fairfax, Prince William and Stafford on the upper reaches of the Northern Neck). Future

128 development is expected to continue in these and nearby areas, sprawling north and west in the

129 southern part of the CBVA and south in the northern part of the CBVA (U.S. EPA, 2010). 
134 The goal of this project was to look at large patterns of change in marsh extent, location and

135 habitat type and elucidate potential conflict with development. To do this, we used an approach 136 similar to the Sea Level Over Proportional Elevation (SLOPE) model that has been used in the

137 Gulf of Mexico (US) to examine the impact of sea level rise on tidal freshwater forests (Doyle et 138 al. 2010). Because this approach makes no assumption about accretion rates, plant productivity, 139 or erosion activity (all of which exhibit high variability around the CBVA and for which

140 comprehensive datasets do not exist) it is suitable for a broad scale assessment of marsh change.

142 Modeling of the tidal marsh extent was based on a digital elevation model (DEM) derived from 143 high-resolution, bare earth, lidar data of the CBVA localities (USGS 2010, 2011a, 2011b, 2012, 144 2013, 2015) using ArcGIS software (ESRI, v 10.4.1). DEM grid cell vertical resolution is 0.15 $145 \mathrm{~m}$ and horizontal resolution is $0.76 \mathrm{~m}$.

147 In this approach, we modeled changes in tidal marsh elevations under sea level rise out to 2100 148 (Table 1) and used those tidal marsh elevations to delineate the extent of tidal marsh at $0.15 \mathrm{~m}$ 149 increments of sea level rise. For each elevation step of $0.15 \mathrm{~m}$, the total area of tidal marsh was 150 calculated for each locality, giving a measure of how tidal marsh distribution is projected to 151 change throughout Virginia, based solely on elevation. For the model, starting tidal marsh 152 elevations were $0 \mathrm{~m}-0.61 \mathrm{~m}$ NAVD88 (Table 1 , Time step 1 ), which was considered to be the 153 approximate tidal frame for 2010. The model went through 13 steps, to finish with tidal marsh 154 elevations of $1.83 \mathrm{~m}-2.44$ m NAVD88, projected to occur in approximately 2100. 155 
Vegetated tidal marshes in the CBVA region fall within the elevation range between MSL and

157 HAT. The exact vertical range of the tidal marshes varies somewhat around the estuary, with

158 variations in tidal amplitude. To select an appropriate range for the model, we examined NOAA

159 tide gauge datums at three disparate locations along the estuarine gradient (shown in Fig 1).

160 These tide gauges gave a mean vertical range for tidal marsh elevation of $0.621 \mathrm{~m}$. This was

161 estimated in the model using $0.61 \mathrm{~m}$, since we were constrained by the $0.15 \mathrm{~m}$ (precisely 0.1524

$162 \mathrm{~m}$ ) vertical resolution of the model to a multiple of that value. To test the assumption that a 0.61

163 m tidal frame is a reasonable approximation of tidal marsh area, predicted 2010 modeled tidal

164 marsh areas (step 1, $0 \mathrm{~m}-0.61 \mathrm{~m}$ NAVD88) were extracted from 25 subwatersheds along the

165 mainstem York River, VA. These areas were compared to the areas of tidal marshes from a

166 ground-verified, aerial photograph-derived inventory conducted in 2010 in the same watersheds

167 (methods described in Mitchell et al., 2017) using a regression (JMP 10).

168

169 Estimates of projected dates for each time range were taken from published data on historic

170 relative sea level trends in at Sewell’s Point, Virginia over the past 50 years (Boon \& Mitchell,

171 2015), extrapolated out to 2100. Years are approximate and estimated from the MSL trend curve.

172 Sea level rise trends vary minimally across the Virginia portion of the Chesapeake Bay (Ezer \&

173 Atkinson, 2015) and the resulting estimations of years should be broadly applicable across the 174 modeled region. 
177 Mitchell, 2015).

\begin{tabular}{|ccc|}
\hline $\begin{array}{c}\text { Scenario step } \\
\text { number }\end{array}$ & $\begin{array}{l}\text { Projected vertical tidal marsh elevations } \\
\text { (NA VD88) }\end{array}$ & \\
\hline 1 & $0 \mathrm{~m}-0.61 \mathrm{~m}$ & 2010 \\
\hline 2 & $0.15 \mathrm{~m}-0.76 \mathrm{~m}$ & 2020 \\
\hline 3 & $0.30 \mathrm{~m}-0.91 \mathrm{~m}$ & 2030 \\
\hline 4 & $0.46 \mathrm{~m}-1.07 \mathrm{~m}$ & 2040 \\
\hline 5 & $0.61 \mathrm{~m}-1.22 \mathrm{~m}$ & 2050 \\
\hline 6 & $0.76 \mathrm{~m}-1.37 \mathrm{~m}$ & 2058 \\
\hline 7 & $0.91 \mathrm{~m}-1.52 \mathrm{~m}$ & 2062 \\
\hline 8 & $1.07 \mathrm{~m}-1.68 \mathrm{~m}$ & 2070 \\
\hline 9 & $1.22 \mathrm{~m}-1.83 \mathrm{~m}$ & 2082 \\
\hline 10 & $1.37 \mathrm{~m}-1.98 \mathrm{~m}$ & 2090 \\
\hline 11 & $1.52 \mathrm{~m}-2.13 \mathrm{~m}$ & 2095 \\
\hline 12 & $1.68 \mathrm{~m}-2.29 \mathrm{~m}$ & 2100 \\
\hline 13 & $1.83 \mathrm{~m}-2.44 \mathrm{~m}$ & \\
\hline
\end{tabular}
potential

181 Developed/impervious areas cannot convert to wetland without either 1) removal of the

182 impervious surface, or 2) significant burial of the impervious surface by sediment. In addition,

183 developed areas have economic value, making them likely areas for protection measures that

184 would prevent wetland migration. To examine the importance of developed areas on future

185 marsh migration capacity, current impervious surfaces that are located in the tidal marsh

186 elevation range were identified at each time step. This gives a "best case scenario", assuming no

187 future development into coastal areas. 
In the analysis, Virginia 1m Land Cover dataset (VGIN, 2016) was used to categorize the type of land in the tidal frame for each step as “Developed (with impervious, turf grass and barren areas)

190 and "Undeveloped" (all other categories, e.g., wetland, pasture, forest, agricultural). Areas of 191 marsh within each category were summed by locality and time period.

193 Salinity distribution in the CBVA varies seasonally and annually; for a generalized salinity 194 distribution, we used the Chesapeake Bay Program’s salinity assignments (shown on Figure 1).

195 No attempt was made to project changes in salinity due to the difficulty of balancing sea level 196 rise-induced upstream salinity migration with the potential increases in river flow due to 197 changing precipitation under current projections.

\section{Results}

3.1 Tidal marsh frames as an indicator of tidal marsh extent

A comparison of the 2010 modeled tidal marsh areas (step 1, $0 \mathrm{~m}-0.61 \mathrm{~m}$ NAVD88) with

201 surveyed tidal marshes (digitized from aerial photography and then field-verified; Mitchell et al.

202 2017) showed that the model effectively identified tidal marshes (Figure 2, $\mathrm{R}^{2}=0.89$ ), with

203 overestimation in a few watersheds and minor underestimation in other watersheds.

204 Examination of mapped extents showed that, in general, the model slightly underestimated marsh

205 extents in extensive marshes. This is not unexpected, since in the York River, HAT is 0.69 m

206 above MSL. This issue should be minimal in the lower parts of the estuary, where the tidal marsh

207 frame is closer to the $0.61 \mathrm{~m}$ used in the model. The model also slightly overestimated marsh 208 extents at the tops of some creeks. In these cases, land use frequently indicated that the areas 
were treed/forested_-suggesting that these might be tidal swamp areas (which would not be captured in the TMI dataset) or forested areas transitioning to tidal marsh.

213 In the 2010 tidal frame elevation range there were $850 \mathrm{~km}^{2}$ of potential tidal marsh in the CBVA.

214 This number declines slowly over time steps to a minimum of $331 \mathrm{~km}^{2}$ at Time Step 9

215 (approximately 2078; Figure 3, entire bars). The tidal area then recovers slightly, ending with a 216 net loss of $379 \mathrm{~km}^{2}$ of tidal marshes in 2130, or $43 \%$ of the starting tidal marsh area. Most of the 217 tidal marsh loss will be realized relatively early, by 2050-2080. Following that time period, total 218 tidal marsh extent should remain fairly constant or even expand slightly.

220 However, the geographic distribution of the marsh area will change over time (Figure 4). In the

2212010 time frame (Step 1), 38\% of total tidal marsh area is in Accomack and Northampton

222 Counties (composing Virginia’s Eastern Shore of the Chesapeake Bay), while only 27\% of tidal 223 marshes are found in the Southside region (Norfolk, Chesapeake, Virginia Beach). By the final 224 time step, this has shifted so that the Southside region (particularly Chesapeake and Virginia 225 Beach) has 53\% of all tidal marshes, while the Eastern Shore region has only 11\% of the 226 remaining tidal marshes. A similar shift in marsh distribution can be seen between the lower and 227 upper parts of the York River (shown in Figure 4 insets). This means that upland areas in 228 localities where marsh expansion is likely are the most critical preservation targets to ensure 229 marsh migration. 
232 Under current development conditions, 2-36\% of the area in each time step’s tidal elevation

233 range is developed (Figure 3a, hatched portion of bars). The proportion of developed area in the

234 tidal frame increases over time as the tidal frame migrates upland, limiting the likely area of tidal

235 marsh. The proportion of impervious surface varies by location as well as through time (Figure

236 5a and b). In the low elevation urban localities (e.g., Hampton), there are ample lands in the

237 future tidal elevation range for marsh migration. However, the majority of those lands are

238 already developed. Only a small fraction of the appropriate elevations are currently natural lands.

239 In the low elevation rural localities (e.g., Mathews), the percentage of impervious surface

240 currently in the projected tidal elevation ranges is low. If future coastal development is

241 discouraged, tidal marsh areas will be essentially consistent over time in these localities.

\subsection{Marsh salinity distributions}

244 Concurrent with an overall decline in marsh area, there is an increase in the dominance of salt

245 marsh communities (mesohaline and poly/euhaline areas) and a reduction in the proportion of

246 oligohaline and tidal freshwater marshes (Figure 6). In the first time step (i.e., 2010), 36\% of

247 marsh acreage is tidal freshwater/oligohaline, and 64\% is salt marsh. By 2050 (step 5), only

$24823 \%$ of the remaining marsh acreage is tidal freshwater/oligohaline, while $76 \%$ of marsh acreage

249 is salt marsh. This translates to a greater than 50\% loss in both tidal freshwater and oligohaline

250 marsh area compared to current marsh extent. Because this study did not include upstream

251 salinity migration, this shift is entirely driven by the expansion/enhanced persistence of ocean 
and bay-front marshes (which are dominated by saltmarsh communities) and the loss of tributary marshes (dominated by tidal freshwater and oligohaline marsh communities).

\section{Discussion}

256 When planning for the future, it is important to understand the distribution of natural resources,

257 how they will change and which changes will be affected by management decisions. It is clear

258 from this analysis that tidal marsh area in the CBVA will tidal marsh area will decline over time

259 (assuming no vertical accretion and thus inevitable loss of existing wetlands that occur at

260 elevations below future intertidal elevations), and that much of this decline is likely to occur

261 within this century. In addition, there will be shifts in the distribution of tidal marshes leading to

262 an increase in salt marshes and a decline in the oligohaline and tidal freshwater marshes that will

263 alter ecological connections and functions. However, management decisions, particularly in the

264 low elevation areas can maximize future tidal marsh extent. Although this study was conducted

265 in the Virginia portion of the Chesapeake Bay, its results are applicable to many estuarine

266 systems, where elevations rise and salinities decline with distance from the coast.

268 Our study shows that predicted patterns of future marsh expanse vary spatially with differences

269 in geomorphology and land use (Mitchell et al., 2017). Although, this study shows an overall

270 decrease in tidal marsh extent throughout the CBVA, marsh extents in localities on the main

271 stem of the CBVA will increase. These results are broadly consistent with analyses of historic

272 marsh migration (Schieder et al., 2018), which found significant marsh expansion on lower the

273 main stem of the Chesapeake Bay since the 1800s, but marsh contraction in marshes backed by

274 higher elevations. Lower main stem localities in the Chesapeake Bay have low elevations which 
275 provide ample land for marsh expansion, coupled with the currently low human development in

276 many of these areas. Hampton, Norfolk and Virginia Beach are exceptions with their high

277 development, and the cost of this development is evident in the low amount of natural lands

278 available for future marsh migration.

279

280 In addition to changes in the distribution of marsh extent, the pattern of topography in the

281 Chesapeake Bay region is predicted to drive a shift in the distribution of marsh ecotypes over

282 time. As bay-front marshes expand, oligohaline and tidal freshwater marshes (particularly those

283 in headwater systems) contract. This is likely to have significant ecological impacts due to a

284 decline in important tidal marsh habitats and a reduced potential for groundwater interception

285 and filtering at the heads of the estuaries as marsh acreage in these areas declines. This study did

286 not attempt to project sea level rise-induced changes in salinity; however, it is important to note

287 that upstream migration of salinity is predicted in the Chesapeake Bay (Hong \& Shen, 2012) and

288 that this will further reduce the proportion of tidal freshwater marshes in projected distributions

289 unless increased precipitation is sufficient to counter the salinity migration.

$290 \quad 4.1$ Interaction of sea level rise, accretion and erosion

291 Factors not explicitly considered in this analysis that can impact marsh persistence include marsh

292 accretion and erosion rates. These factors could cause the model to over- or underestimate the

293 rate of future marsh changes in locations where they are of importance (e.g., areas of high

294 erosion or large potential sediment loading). Both marsh erosion and accretion rates are known

295 to vary around the Chesapeake Bay; since there are no comprehensive data sets on these rates for

296 CBVA marshes or future projections of how those rates will change under sea level rise, they 
could not be quantitatively included in the analysis. However, their critical parameters are

298 discussed in this section.

300 The contribution of marsh accretion to future marsh extent is still an open question. Marsh

301 accretion is a factor of both in situ organic production rates and allocthonous sediment retention.

302 It is the hardest variable to project into the future, since climatic shifts can affect plant

303 productivity (e.g. C3 plant production under increased $\mathrm{CO}_{2}$; Drake, 2014) and sediment supply

304 (e.g. sediment erosion under increased precipitation intensity; Williams et al. 2017). Marsh plant

305 production rates and local sediment supply are highly variable, but a geographically expansive

306 survey suggests that there is a theoretical limit to sediment accretion of $5 \mathrm{~mm} \mathrm{yr}^{-1}$, suggesting

307 that current rates of sea level rise on the Atlantic coast are already at a level that will lead to

308 eventual marsh drowning (Morris et al., 2016). The sea level rise trend in the CBVA over the

309 past 30 years has exceeded $5 \mathrm{~mm} \mathrm{yr}^{-1}\left(5.86 \mathrm{~mm} \mathrm{yr}^{-1}\right.$ at the mouth of the Bay; Ezer \& Atkinson,

3102015 ) and is predicted to accelerate (Boon \& Mitchell, 2015). During the same time period,

311 sediment loads to the Chesapeake Bay (a potential source of allochthonous sediment contribution

312 to marshes) have declined due to management actions (Gellis et al., 2004). Explicit TSS

313 reduction goals for the Chesapeake Bay (http://www.epa.gov/chesapeake-bay-tmdl) are designed

314 to continue aggressive sediment management into the future. These reductions in sediment

315 supply coupled with the predicted acceleration in sea level rise could constrain marsh accretion

316 potential, impacting future marsh persistence. Even in areas with high sediment supply, rates of

317 relative sea level rise above $10.2 \mathrm{~mm} \mathrm{yr}^{-1}$ are predicted to be unsustainable for marshes (Morris et

318 al., 2002). Under current rates of acceleration (0.119 $\mathrm{mm} \mathrm{yr}^{-2}$; Boon et al., 2018), relative sea

319 level rise in the CBVA will exceed those values within 60 years. However, previous studies in 
the Chesapeake Bay have shown a time lag between the time when sea level rise rates exceeded

321 local accretion rates and the subsequent marsh loss (Kearney et al., 2002), suggesting that tidal

322 marsh loss in the next couple decades will be controlled more by erosion rates than drowning due 323 to sea level rise.

325 It is important to note, that even in a region with high rates of sea level rise and declining

326 sediment supply, such as CBVA, there are marshes where progradation of the shoreline has been

327 observed over the past 30 years (Mitchell et al., 2017). This emphasizes the point that sediment

328 supply can be localized, and in some areas is sufficient to compensate for changes in the tidal

329 frame elevation. Although these marshes are unusual compared to the marshes in the entire

330 study area of Mitchell et al. (2017), it is reasonable to assume that they, and marshes in areas of

331 similarly high sediment supply, will maintain their extent longer than predicted in this study.

332 This is also broadly in agreement with Schieder et al. (2018), which found that some marshes in

333 the upper tributaries contracted and some expanded over the historic period studied.

335 Erosion rates are highly variable along CBVA shorelines, even sometimes within close

336 geographic proximity. Although relatively stable over the past 60 year (Kirwan et al., 2016),

337 erosion rates are predicted to increase with accelerating sea level rise, potentially resulting in

338 huge coastal losses (Leatherman et al., 2000; Mariotti \& Fagherazzi, 2010). On average,

339 localities on the main stem of the CBVA experience low to moderate $\left(0.3-1.5 \mathrm{~m} \mathrm{yr}^{-1}\right)$ erosion on

$34030 \%$ of their shorelines (Milligan et al., 2012). Exceptions are heavily stabilized shorelines such

341 as those in Norfolk. Main stem CBVA marshes are considered one of the more stable CBVA

342 shoreline environments, eroding at $0.54-0.66 \mathrm{~m} \mathrm{yr}^{-1}$, depending on the underlying substrate 
343 (Rosen, 1980). Rates on the tributaries are generally lower (e.g., York River marshes are eroding

344 at $0.21 \mathrm{~m} \mathrm{yr}^{-1}$; Byrne \& Anderson, 1978) and erosion in the creeks is generally negligible. Given

345 these rates, the marshes where erosion rates will most affect marsh acreage are located in the

346 same localities where much of the marsh expansion is projected (e.g., Gloucester, Mathews). The

347 balance between marsh erosion and marsh migration will vary over time depending on their

348 relative trends (i.e., linear vs. accelerating rise), and the impact to marsh acreage will be highly

349 dependent on the slope of the shoreline (Figure 7). However, it is expected that erosion will

350 result in the loss of some of the projected marsh acreage; therefore, the numbers in the study may

351 be overestimating future marsh extent, particularly where there are narrow, fringing marshes that

352 could erode before having the opportunity to migrate significantly.

353

354 Shoreline stabilization placed at the front edge of a marsh will reduce or eliminate erosion, while

355 allowing marsh migration. However, where shoreline stabilization is placed landward of the

356 marsh, erosion of the marsh will continue while marsh migration will be blocked until the

357 elevation of the stabilizing structure is topped. This may lead to a temporary loss of marsh in

358 heavily stabilized areas, even with low gradient shorelines, or longer-term loss if stabilization

359 structures are tall. Tidal marshes should re-establish following overtopping of stabilization

360 structures by the tidal frame, but the ecological structure and ecosystem services associated with

361 those marshes may be difficult to re-establish, particularly if the new plant community differs

362 from the original. 
365 Maximizing future tidal marsh extent will require prioritization of undeveloped land preservation

366 in low elevation lands contiguous to the shoreline. A clear policy consideration resulting from

367 this study is that a uniform state-wide management policy will not maximize future tidal marsh

368 extent unless that policy is specifically tied to elevations (e.g., minimizing development in lands

369 below $0.91 \mathrm{~m}$ (3 ft) NAVD88). In localities with shallow shoreline elevation gradients, passive

370 measures (such as the preservation of undeveloped lands) can be a powerful management action,

371 assuming that extensive undeveloped lands exist. However, in localities with steep shoreline

372 gradients, tidal marsh persistence will require more active measures and may eventually be

373 futile. Active management in these areas may include the construction of "living shorelines" to

374 replace or expand dwindling marsh extents or thin-layer deposition to help existing marshes

375 maintain their elevation in relative to rising sea level (Wigand et al., 2017).

376 In highly developed/urban areas, tidal marshes may be of particular ecological importance since

377 they are often scarce and therefore the remaining marshes represent critical refuges for faunal

378 marsh residents. In the Chesapeake Bay, many of the localities with shallow shoreline elevation

379 gradients are also highly urbanized and expanding. In these localities, tidal marshes have the

380 capacity to expand and become less fragmented under sea level rise. However, that endpoint

381 requires aggressive preservation of remaining undeveloped lands in tidal marsh migration

382 corridors and consideration of the active removal of impervious surfaces as they become

383 inundated to allow marsh development. This type of activity is contrary to the actions taken by

384 many urban areas under pressure from flooding and sea level rise. Rising water levels are 
frequently met with shoreline hardening and coastal barriers, which can preserve or improve property values (Jin et al., 2015). Less frequently used, managed retreat/realignment and rolling

387 easements, where development is gradually moved out of the water's path, is the adaptation that 388 is most in line with the goal of maximizing future tidal marsh extents. However, this option is 389 challenging to implement and requires collaboration between property owners and all levels of 390 government to align private and public economic and resiliency goals. Other adaptations that 391 allow a balance between protection of human infrastructure and tidal marshes include storm 392 surge barriers (which allow natural tidal action except during storm events) and the use of natural 393 features (such as beach nourishment or marsh creation) to alleviate storm-associated flooding.

\section{Conclusions}

396 Overall, tidal marsh extent is predicted to decline significantly in the Chesapeake Bay over the 397 next 50-60 years due to sea level rise. However, the future distribution of tidal marsh complexes 398 depends on their location within the geological and human landscape. In low elevation areas, 399 significant marsh expansion is possible. While in urbanized areas, rising sea levels and increased 400 flooding will create additional pressures to shoreline ecosystems, and may conflict with local 401 efforts to protect their infrastructure. Where low elevation areas overlap with urban shorelines, 402 current and future policy decisions will be a critical determinant of future tidal marsh extent. 403

404 The future of tidal marsh complexes is highly dependent on their location within the geological 405 (elevation) and human (impervious surface) landscape. Not all areas of the Chesapeake Bay have 406 land elevations suitable for marsh retreat/migration. Low salinity areas, where fresh and 

future. The loss of marsh extent from these locations have the potential to impact the entire estuarine ecology. These losses will be difficult to mitigate, so it is important to understand the greater ramifications of this change.

\section{Acknowledgments, Samples, and Data}

413 No authors have any financial conflicts of interest or affiliations that might lead to conflicts of

414 interest. This research was supported in part by grants from the National Science Foundation

415 and the Environmental Protection Agency. The data supporting the conclusions of this paper may

416 be found in publications and data cited in the reference section. This paper is Contribution No.

4173975 of the Virginia Institute of Marine Science, William \& Mary.

\section{References}

419 Arheimer B, Torstensson G, Wittgren HB (2004) Landscape planning to reduce coastal

420 eutrophication: agricultural practices and constructed wetlands. Landscape and Urban Planning, 421 67(1-4): 205-215

423 Bierwagen BG, Theobald DM, Pyke CR, Choate A, Groth P, Thomas JV, Morefield P (2010)

424 National housing and impervious surface scenarios for integrated climate impact assessments.

425 Proceedings of the National Academy of Sciences, 107(49):20887-20892

Bilkovic DM, Mitchell MM (2017) Designing living shoreline salt marsh ecosystems to promote coastal resilience. In Living Shorelines: The Science and Management of Nature-based Coastal Protection. (Eds: Bilkovic DM, Mitchell M, Toft J, La Peyre, M) Taylor \& Francis Group and

432 Boon JD (2012) Evidence of sea-level acceleration at US and Canadian tide stations, Atlantic 433 Coast, North America. Journal of Coastal Research, 28(6):1437-1445 
Boon JD, Mitchell M, Loftis JD, Malmquist DM (2018) Anthropocene Sea Level Change: A History of Recent Trends Observed in the U.S. East, Gulf, and West Coast Regions. Special Report in Applied Marine Science and Ocean Engineering (SRAMSOE) No. 467. Virginia Institute of Marine Science, College of William and Mary. https://doi.org/10.21220/V5T17T

Bromberg KD, Bertness MD (2005) Reconstructing New England salt marsh losses using historical maps. Estuaries and Coasts, 28(6):823-832 Applied Marine Science and Ocean Engineering No. 111, Virginia Institute of Marine Science, Gloucester Pt, VA, 102p.

CCRM [Center for Coastal Resources Management] Digital Tidal Marsh Inventory Series (2017) William and Mary, Gloucester Point, Virginia, 23062

Chmura GL (2013) What do we need to assess the sustainability of the tidal salt marsh carbon sink? Ocean \& Coastal Management, 83:25-31

Church JA, White NJ (2011) Sea-level rise from the late 19th to the early 21st century. Surveys in geophysics, 32(4-5):585-602 human impacts reverse centuries of carbon sequestration and salt marsh accretion. PLoS One, 9(3): e93296 tidal forests along the northern Gulf of Mexico under sea-level rise. Forest Ecology and Management, 259(4):770-777

Drake BG (2014) Rising sea level, temperature, and precipitation impact plant and ecosystem responses to elevated CO2 on a Chesapeake Bay wetland: review of a 28-year study. Global

472 Eggleston J, Pope J. (2013) Land subsidence and relative sea-level rise in the southern 473 Chesapeake Bay region: U.S. Geological Survey Circular 1392, 30 p., 474 http://dx.doi.org/10.3133/cir1392 
Ezer T (2013) Sea level rise, spatially uneven and temporally unsteady: Why the US East Coast, the global tide gauge record, and the global altimeter data show different trends. Geophysical

Ezer T, Atkinson, LP (2014) Accelerated flooding along the US East Coast: on the impact of sealevel rise, tides, storms, the Gulf Stream, and the North Atlantic oscillations. Earth's Future,

Ezer T, Atkinson, LP (2015) Sea Level Rise in Virginia - Causes, Effects and Response.

Feagin, RA, Martinez, M., Mendoza-Gonzalez, G, Costanza, R (2010.) Salt marsh zonal migration and ecosystem service change in response to global sea level rise: a case study from an urban region. Ecology and Society, 15(4) [online] URL: http://www.ecologyandsociety.org/vol15/iss4/art14/

Gellis AC, Banks WS, Langland MJ, Martucci SK (2004) Summary of suspended-sediment data for streams draining the Chesapeake Bay watershed, water years 1952-2002. US Geological Survey Scientific Investigations Report, 5056, pp.1-59

Gittman RK, Fodrie FJ , Popowich AM, Keller DA, Bruno JF, Currin CA., Peterson CH, Piehler, MF (2015) Engineering away our natural defenses: an analysis of shoreline hardening in the US.

Hartig EK, Gornitz V, Kolker A, Mushacke F, Fallon D (2002) Anthropogenic and climatechange impacts on salt marshes of Jamaica Bay, New York City. Wetlands, 22(1):71-89

Hong B, Shen J (2012) Responses of estuarine salinity and transport processes to potential future sea-level rise in the Chesapeake Bay. Estuarine, Coastal and Shelf Science, 104:33-45

Jin D, Hoagland P, Au DK, Qiu J (2015) Shoreline change, seawalls, and coastal property values. Ocean \& Coastal Management, 114:185-193 

(2002) Landsat imagery shows decline of coastal marshes in Chesapeake and Delaware Bays.

Kirwan ML, Walters DC, Reay WG, Carr JA (2016) Sea level driven marsh expansion in a coupled model of marsh erosion and migration. Geophysical Research Letters, 43(9):4366-4373

Mariotti G, Fagherazzi S (2010) A numerical model for the coupled long-term evolution of salt marshes and tidal flats, Journal of Geophysical. Research, 115: F01004, doi:10.1029/2009JF001326

Minello TJ, Rozas LP, Baker R (2012) Geographic variability in salt marsh flooding patterns may affect nursery value for fishery species. Estuaries and Coasts, 35(2):501-514

Milligan DA, Wilcox C, Cox MC, Hardaway CS (2012) Shoreline Evolution Update: 1937/382009 End Point Rate Calculations Counties of Accomack, Gloucester, and York Cities of Newport News, Norfolk, and Poquoson. Virginia Institute of Marine Science, College of William and Mary. https://doi.org/10.21220/V5213G

Mitchell M, Herman J, Bilkovic DM Hershner C (2017) Marsh persistence under sea-level rise is controlled by multiple, geologically variable stressors, Ecosystem Health and Sustainability, 3:10, DOI: 10.1080/20964129.2017.1396009

Morris JT, Sundareshwar PV., Nietch CT, Kjerfve B, Cahoon DR (2002) Responses of coastal wetlands to rising sea level. Ecology, 83(10):2869-2877

Morris JT, Barber DC, Callaway JC, Chambers R, Hagen SC, Hopkinson CS, Johnson BJ, matter to sediment volume and accretion in tidal wetlands at steady state. Earth's future, 4(4):110-121

Neumann B, Vafeidis AT, Zimmermann J, Nicholls RJ (2015) Future coastal population growth and exposure to sea-level rise and coastal flooding-a global assessment. PloS one, 10(3) p.e0118571 
Rosen, P.S. (1980) Erosion susceptibility of the Virginia Chesapeake Bay shoreline. Marine

552 Geology, 34(1-2):45-59

554 Shepard CC, Crain, C.M., Beck, M.W. (2011) The Protective Role of Coastal Marshes: A Systematic Review and Meta-analysis. PLoS ONE 6(11):e27374. doi:10.1371/journal.pone.0027374

557

558

559

560

561

562

563

564

565

566

567

568

569

570

571

572

573

574

575

576

577

578

579

580

581

582

583

584

585

Small C, Nicholls RJ (2003) A Global Analysis of Human Settlement in Coastal Zones. Journal of Coastal Research, 19 (3):584-599

Sweet WV, Park J (2014) From the extreme to the mean: Acceleration and tipping points of coastal inundation from sea level rise. Earth's Future, 2(12):579-600

U.S. EPA. ICLUS Tools \& Datasets (Version 1.3.2). (2010) U.S. Environmental Protection Agency, Washington, DC, EPA/600/R-09/143F

USGS (2010) USGS Bare Earth DEM ARRA-VA_11County_2010, multiple tiles, U.S.

Geological Survey sciencebase.gov 2014-09-11, access through https://vgin.maps.arcgis.com

USGS (2011a) USGS Bare Earth DEM VA_FEMA_KingWilliamCo_2011, multiple tiles, U.S. Geological Survey sciencebase.gov 2014-09-11, access through https://vgin.maps.arcgis.com

USGS (2011b) Bare Earth DEM VA_FEMA_MiddleCounties_2011, multiple tiles, U.S.

Geological Survey sciencebase.gov 2014-09-11, access through https://vgin.maps.arcgis.com

USGS (2012) Bare Earth DEM VA-WV-MD_FEMA_Region3_UTM18_2012, multiple tiles, U.S. Geological Survey sciencebase.gov 2014-09-16, access through

https://vgin.maps.arcgis.com

USGS (2013) USGS Bare Earth DEM VA Norfolk 2013, multiple tiles, U.S. Geological Survey sciencebase.gov 2015-05-22, access through https://vgin.maps.arcgis.com

USGS (2015) USGS Bare Earth DEM VA Eastern-Shore BAA 2015, multiple tiles, U.S. Geological Survey sciencebase.gov 2017-05-09, access through https://vgin.maps.arcgis.com 
Valiela I, Cole ML (2002) Comparative evidence that salt marshes and mangroves may protect

589 VGIN [Virginia Geographic Information Network]. (2016) Virginia 1m Land Cover dataset.

590 access through https://vgin.maps.arcgis.com

591

592 Wigand C, Ardito T, Chaffee C, Ferguson W, Paton S, Raposa K, Vandemoer C, Watson E 593 (2017) A climate change adaptation strategy for management of coastal marsh systems. Estuaries 594 \& Coasts, 40(3):682-693

595

596 Williams MR, Bhatt G, Filoso S, Yactayo G (2017) Stream Restoration Performance \& Its 597 Contribution to the Chesapeake Bay TMDL: Challenges Posed by Climate Change in Urban 598 Areas. Estuaries \& Coasts, 40(5):1227-1246

599

600 
Figure 1. Virginia portion of the Chesapeake Bay (referred to in the text as "CBVA"). Localities

604 are labeled. Approximate split between fresh and brackish water is shown.

605

606 Figure 2. Comparison of predicted marsh area to field-verified marsh area $\left(\mathrm{m}^{2}\right)$ in 25

607 subwatersheds on the mainstem York River, VA.

608

609 Figure 3. Predicted changes in area $\left(\mathrm{m}^{2}\right)$ within the tidal marsh elevation frame over time.

610 Scenario steps are $0.61 \mathrm{~m}$ in range and move up $0.15 \mathrm{~m}$ in elevation with each step. The time steps

611 can be related to sea level rise projections using the information in Table 1. Solid portions of the

612 bars indicate areas that are pervious (natural lands) in the projected tidal elevations. Hatched

613 portions of the bars indicate areas that are currently impervious surfaces. These areas would

614 have to be remediated to allow tidal marshes to establish through migration.

615

616 Figure 4. Changing distribution of marshes in Chesapeake Bay, VA between current tidal

617 envelope and predicted tidal envelope for 2100. Insets show two areas with different prognosis

618 based on elevation.

619

620 Figure 5. Total projected marsh area over time in two low elevation localities (a) Hampton

621 (urban) and (b) Mathews (rural). Solid portions of the bars indicate areas that are pervious

622 (natural lands) in the projected tidal elevations. Hatched portions of the bars indicate areas that

623 are currently impervious surfaces. These areas would have to be remediated to allow tidal

624 marshes to establish through migration. Scenario steps are $0.61 \mathrm{~m}$ in range and move up $0.15 \mathrm{~m}$ in 
625 elevation with each step. The time steps can be related to sea level rise projections using the

626 information in Table 1.

627

628 Figure 6. Projected changes in marsh area by salinity type over time. Scenario steps are $0.61 \mathrm{~m}$ in

629 range and move up $0.15 \mathrm{~m}$ in elevation with each step. The time steps can be related to sea level

630 rise projections using the information in Table 1.

631

632 Figure 7. A conceptual graph showing the importance of slope in determining the dominant

633 process determining affecting marsh size over time. The figure considers the balance between

634 steady erosion and accelerating sea level rise-driven marsh migration. This figure assumes a

635 steady erosion rate of $0.6 \mathrm{~m} \mathrm{yr}^{-1}$ (Rosen 1980) and a sea level rise rate of $5.11 \mathrm{~mm} \mathrm{yr}^{-1}$,

636 accelerating at $0.0169 \mathrm{~mm} \mathrm{yr}^{-2}$ (Boon and Mitchell 2015). On steep slopes, erosion is the

637 dominant force controlling marsh change; however, on gradual slopes, migration becomes the

638 dominant force as sea level rise acceleration increases rise rates.

639 


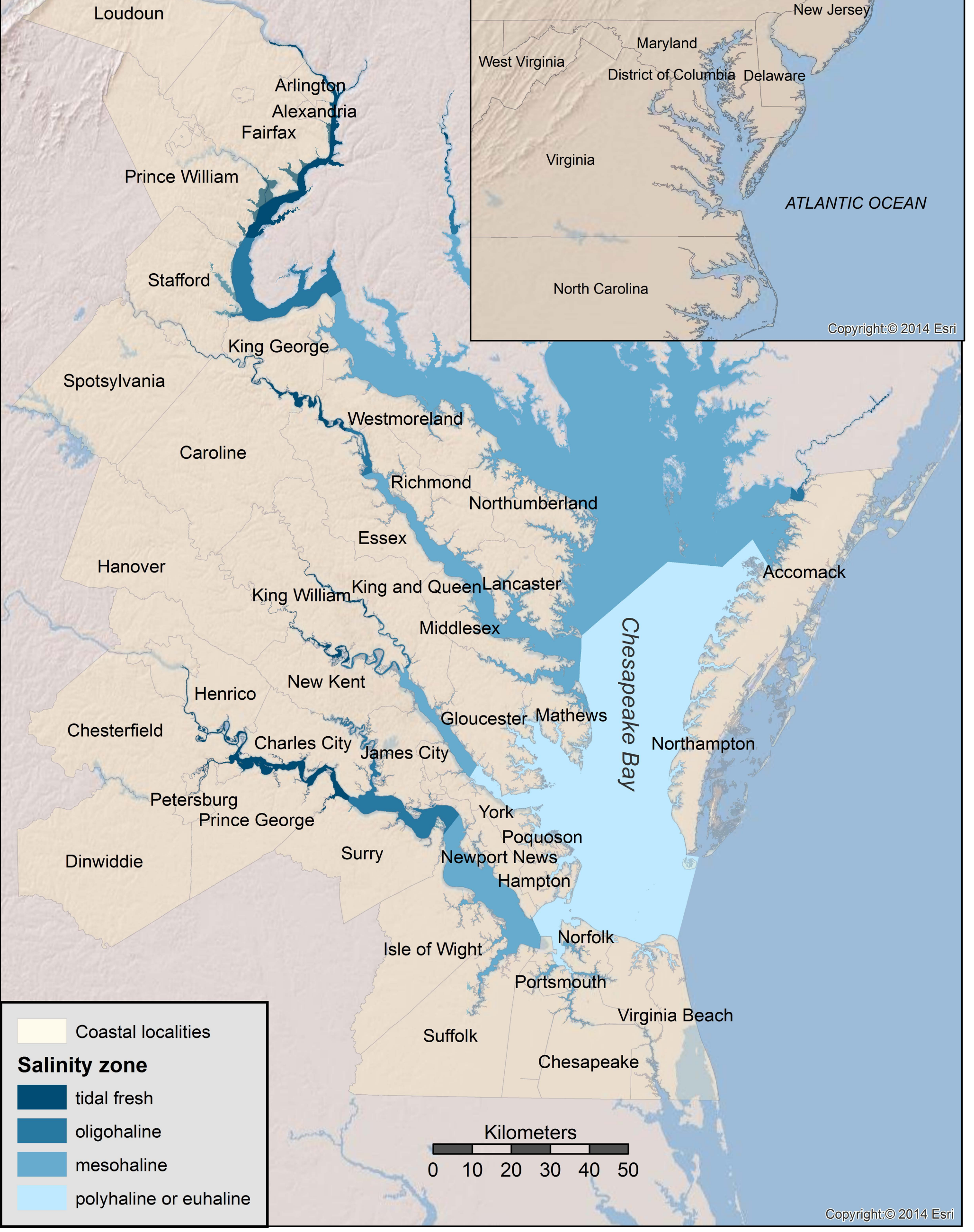


Comparison of model with surveyed data

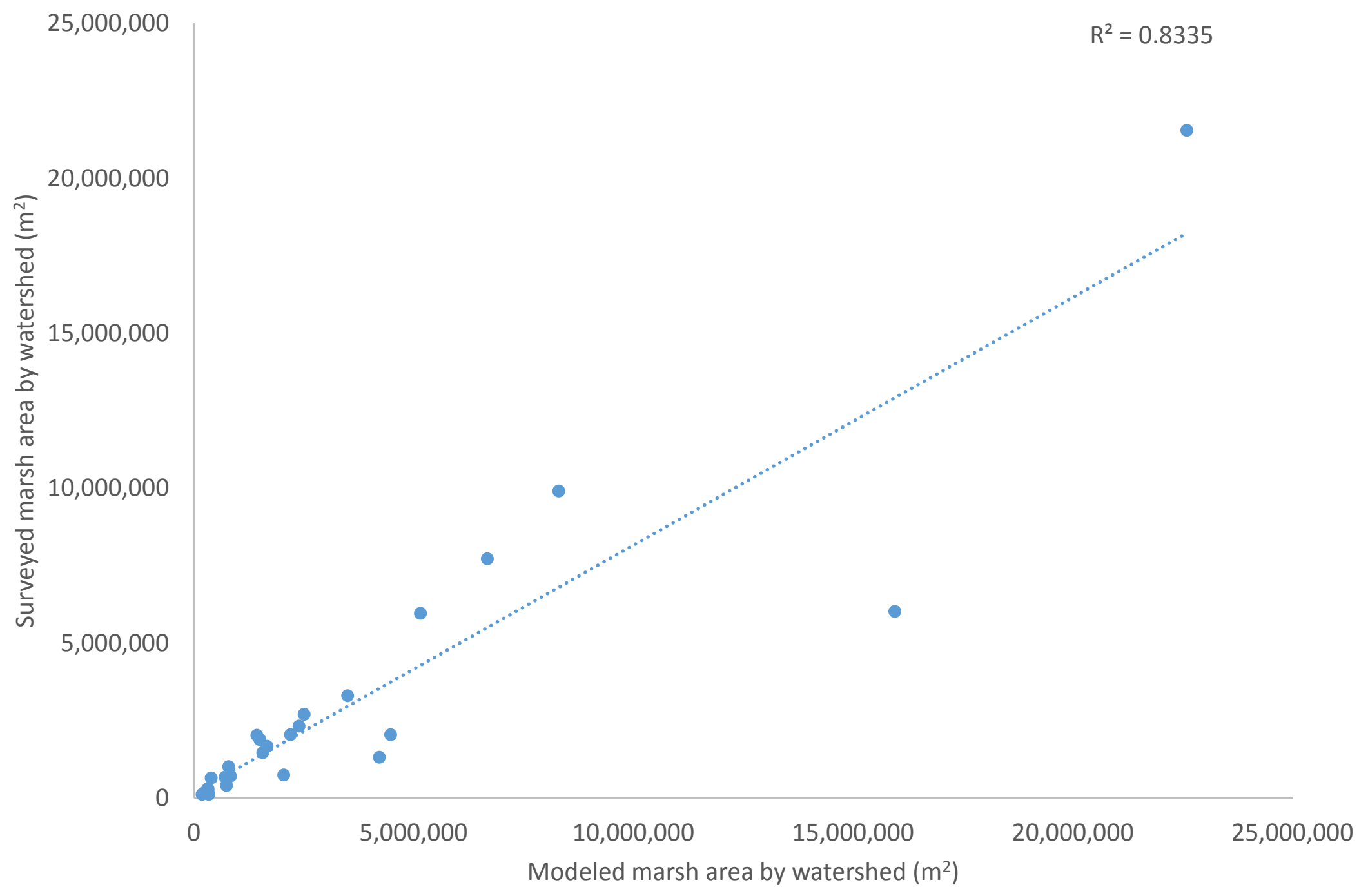


VA Bay Modeled Marsh Area

undeveloped $\mathbf{\text { developed }}$

$1,000,000,000$

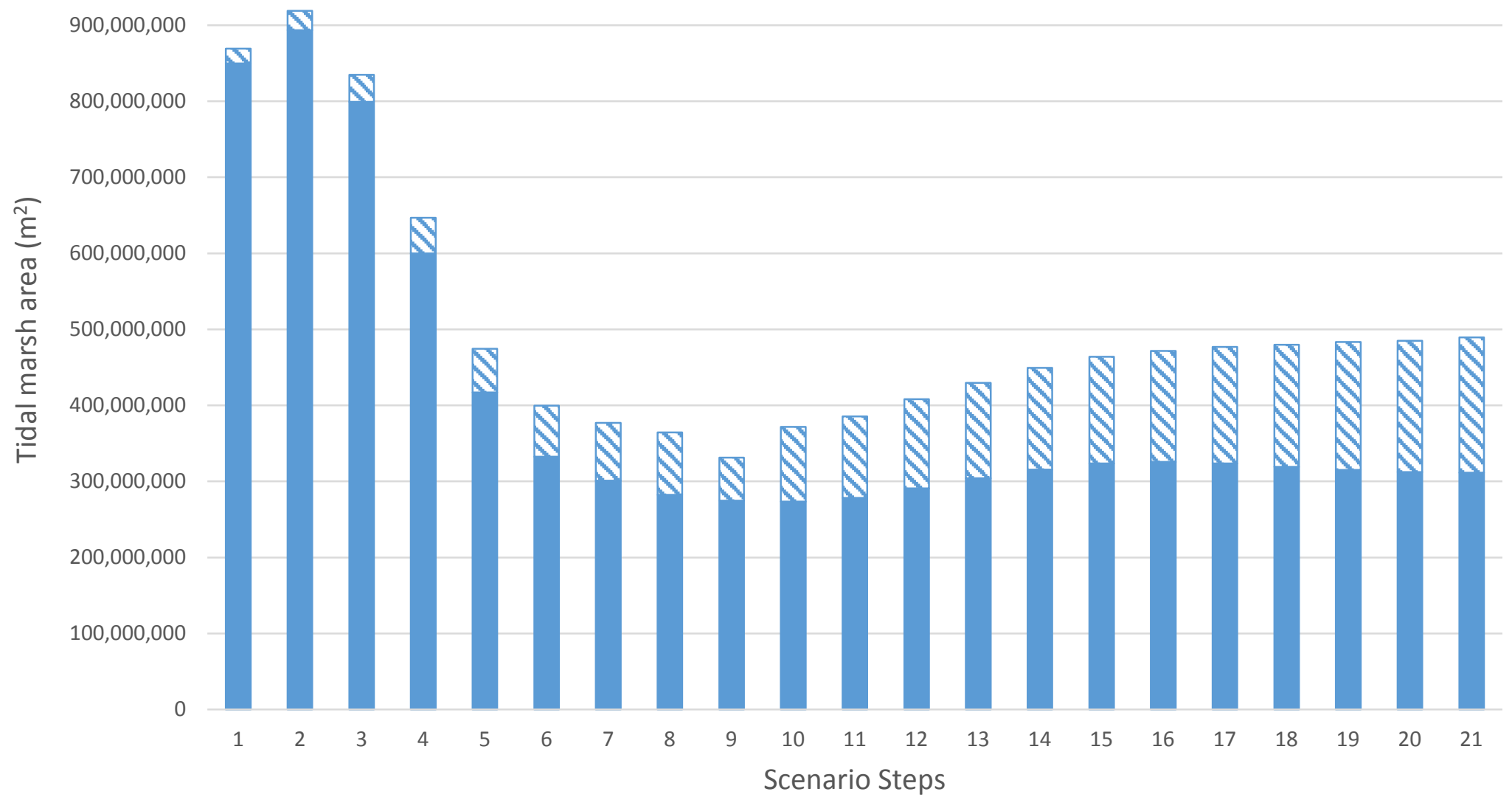




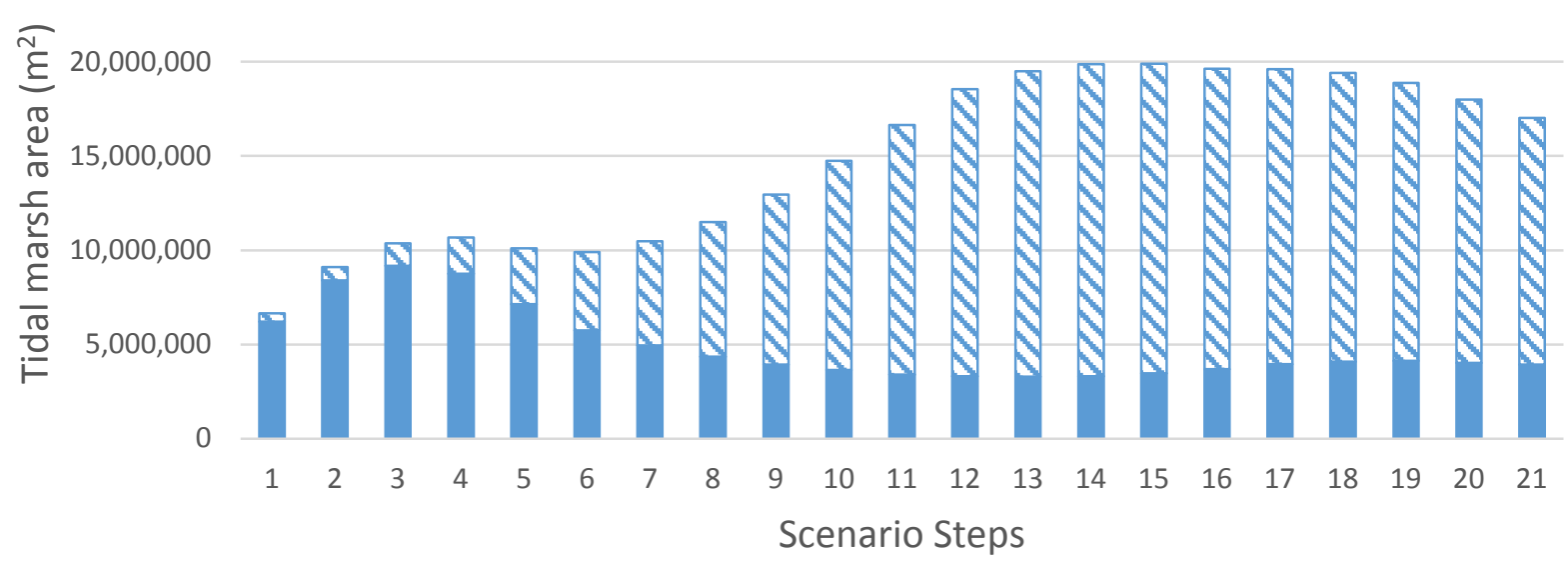

\section{Mathews}

b)

undeveloped $\Delta$ developed

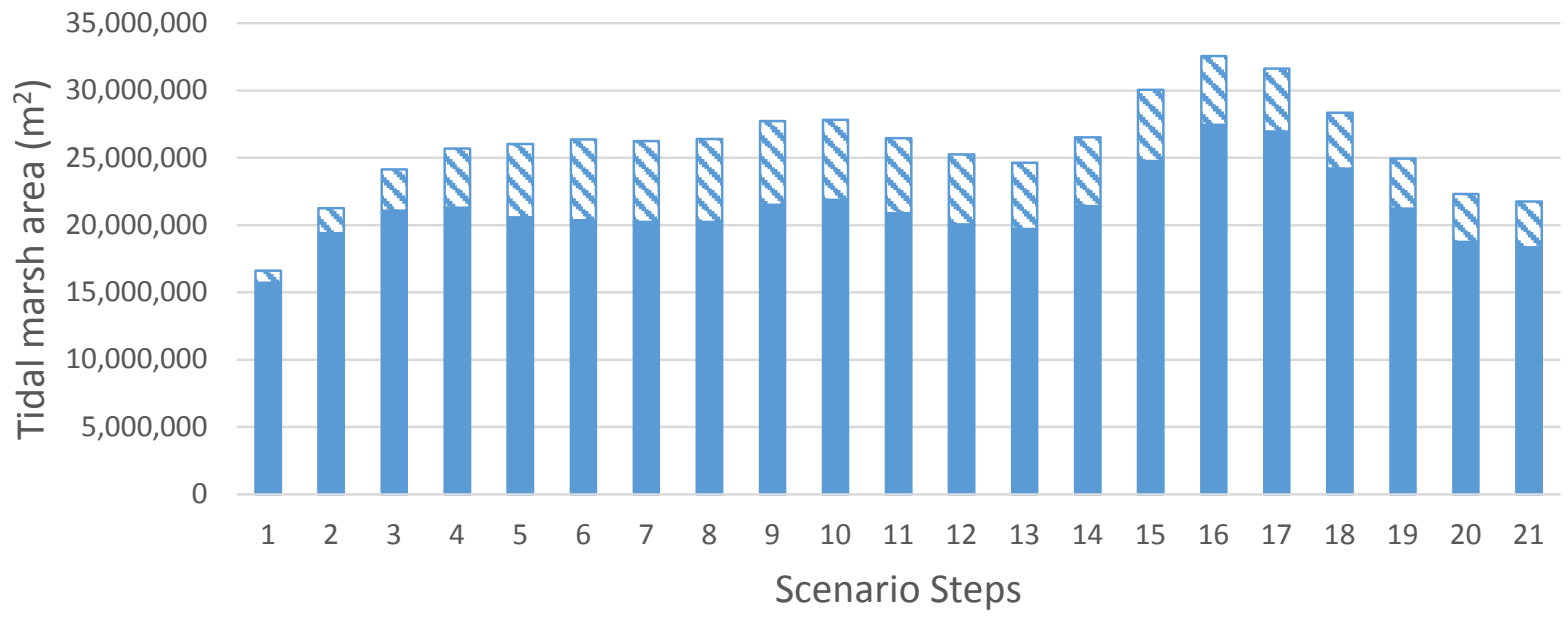




\section{Projected marsh area in VA Bay}

Tidal fresh 四Oligohaline Mesohaline OPolyhaline/euhaline

$1,000,000,000$

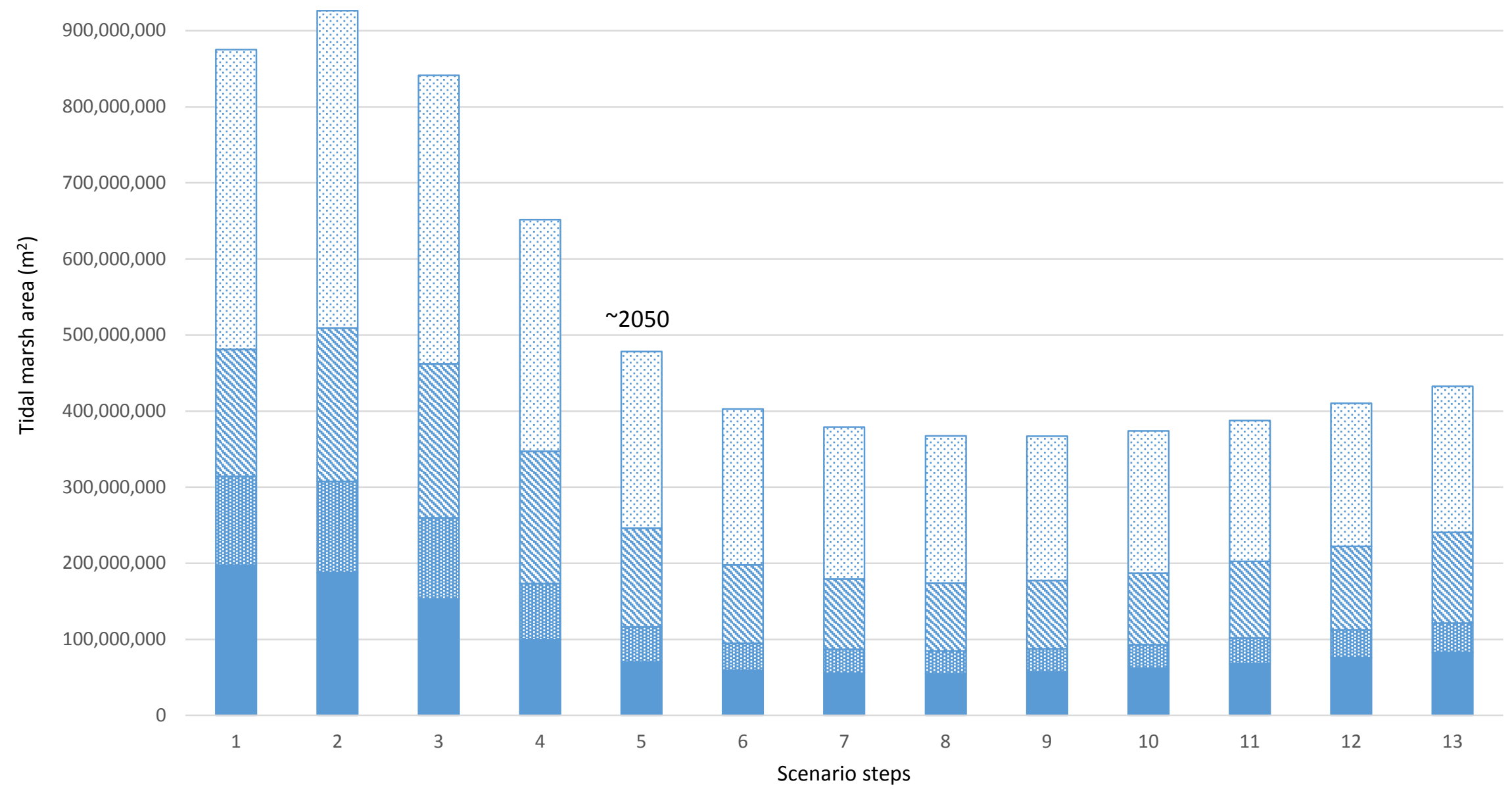




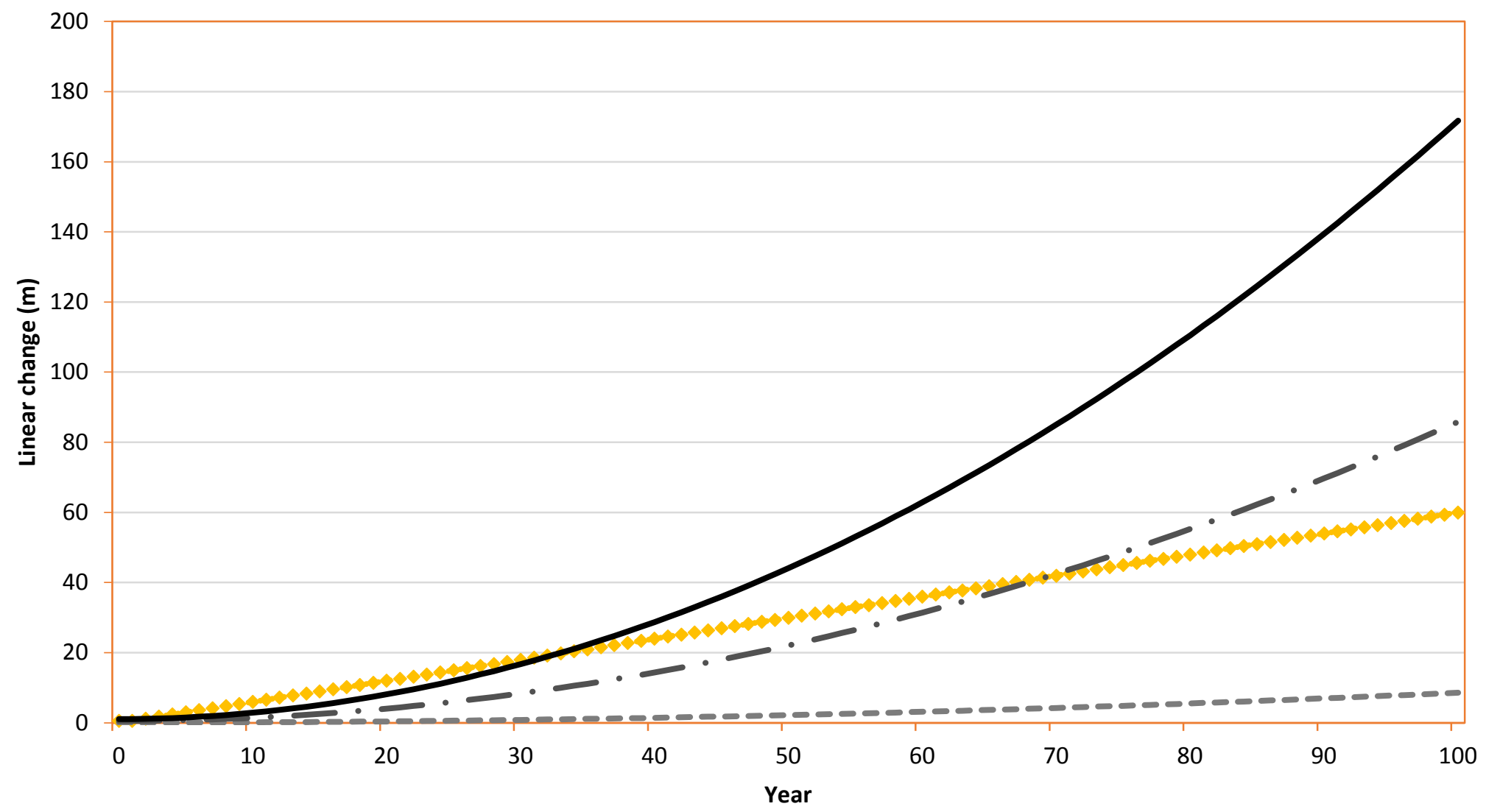

$\cdots \cdots$ loss from erosion $\quad-\infty$ migration 1:10 slope $\quad \longrightarrow$ migration 1:100 slope $\quad$ migration 1:200 slope 